Article

\title{
Brazilian Red Propolis Is as Effective as Amoxicillin in Controlling Red-Complex of Multispecies Subgingival Mature Biofilm In Vitro
}

\author{
Kadmo Azevedo de Figueiredo ${ }^{\dagger}$, Helio Doyle Pereira da Silva ${ }^{\dagger}$, Stela Lima Farias Miranda, \\ Francisco Jerfeson dos Santos Gonçalves, Arlene Pereira de Sousa, \\ Luciene Cristina de Figueiredo, Magda Feres and Bruno Bueno-Silva *(D) \\ Dental Research Division, Guarulhos University, Guarulhos, São Paulo, Guarulhos 07023-070, Brazil; \\ kadmodonto@hotmail.com (K.A.d.F.); heliodoyle@yahoo.com.br (H.D.P.d.S.); \\ stelalima.odonto@hotmail.com (S.L.F.M.); francisco.jerfeson@outlook.com (F.J.d.S.G.); \\ arlenesousa1@gmail.com (A.P.d.S.); lucienedefigueiredo@gmail.com (L.C.d.F.); mferes@ung.br (M.F.) \\ * Correspondence: Bruno.silva@prof.ung.br \\ + These authors contributed equally to this work.
}

Received: 11 June 2020; Accepted: 19 July 2020; Published: 22 July 2020

\begin{abstract}
This study investigated the effects of Brazilian Red Propolis (BRP) extract on seven-day-old multispecies subgingival biofilms. Mixed biofilm cultures containing 31 species associated with periodontal health or disease were grown for six days on a Calgary device. Then, mature biofilms were treated for $24 \mathrm{~h}$ with BRP extract at different concentrations (200-1600 $\mu \mathrm{g} / \mathrm{mL})$, amoxicillin (AMOXI) at $54 \mu \mathrm{g} / \mathrm{mL}$ (positive control) or vehicle (negative control). Biofilm metabolic activity was determined by colorimetry, and bacterial counts/proportions were determined by DNA-DNA hybridization. Data were analyzed by Kruskal-Wallis and Dunn's tests. Treatment with BRP at 1600, 800 and $400 \mu \mathrm{g} / \mathrm{mL}$ reduced biofilm metabolic activity by $56 \%, 56 \%$ and $57 \%$, respectively, as compared to $65 \%$ reduction obtained with AMOXI. Mean total cell counts were significantly reduced in all test groups ( $50-55 \%)$. Lower proportions of red, green and yellow complex species were observed upon treatment with BRP $(400 \mu \mathrm{g} / \mathrm{mL})$ and AMOXI, but only AMOXI reduced the proportions of Actinomyces species. In conclusion, BRP extract was as effective as AMOXI in killing seven-day-old multispecies biofilm pathogens and did not affect the levels of the host-compatible Actinomyces species. These data suggest that BRP may be an alternative to AMOXI as an adjunct in periodontal therapy. In vivo studies are needed to validate these results.
\end{abstract}

Keywords: propolis; antimicrobial; periodontal disease; amoxicillin

\section{Introduction}

The main etiological factor of periodontal disease is a dysbiosis of the oral subgingival biofilm associated with the presence of periodontopathogens, mainly Porphyromonas gingivalis, Tannerella forsythia, Treponema denticola and Aggregatibacter actinomycetemcomitans. These microorganisms release metabolic byproducts or components (e.g., lipopolysaccharides and fimbriae) into periodontal tissues, causing an exacerbated inflammatory response which leads to tissue destruction [1]. Periodontal diseases are estimated to affect between 20 and 50\% of the world population, with a negative impact on the individual's health-related quality of life [2].

The treatment of periodontal diseases consists of controlling the occurrence of periodontopathogenic microorganisms to reduce or eliminate tissue inflammation. Mechanical removal of subgingival biofilms by means of scaling and root planning (SRP) significantly improves all periodontal clinical parameters. [3]. However, the mechanical therapy alone may not be fully effective to reverse the major 
dysbiosis associated with periodontitis, requiring the use of systemic antibiotics. Systemic administration of amoxicillin (AMOXI) was shown to be an effective adjunctive treatment in the management of periodontitis [4,5]. In addition, the combination of AMOXI and metronidazole (MTZ) with SRP has proven an effective approach [6-8]. However, some essential questions associated with the use of these antibiotics remain unanswered, such as potential systemic side effects and the risk of selecting resistant strains [9].

Natural products, such as propolis, have attracted the interest of researchers and laypeople worldwide due to the recent scientific evidence of their beneficial pharmacological properties [10,11]. Brazilian Red Propolis (BRP) has a unique chemical composition that differs from that of other types of Brazilian propolis. BRP contains mostly polar compounds, which facilitates its dissolution in aqueous vehicles and sustains the presence of several isoflavones-compounds with documented beneficial properties for humans [12]. The main relevant pharmacological actions of BRP include antimicrobial [13-15], anti-inflammatory [16-18], anti-tumoral [19], healing [20], antioxidant and antiparasitic properties [15].

Recently, our research group reported that BRP extract is effective in reducing multispecies subgingival biofilm formation [13], but its effects on mature biofilms remain to be determined. Disruption of mature biofilms by antimicrobial agents is challenging and commonly ineffective since mature biofilm cultures are more virulent than newly formed ones or than planktonic cells [21,22]. Thus, in this study, we investigated the inhibitory effects of BRP extract on mature multispecies subgingival biofilms comparatively to AMOXI.

\section{Results}

Figure 1 shows the effects of BRP extract and controls on the metabolic activity of multispecies biofilm cells. Treatment with BRP extract at 1600, 800 and $400 \mu \mathrm{g} / \mathrm{mL}$ significantly reduced biofilm metabolic activity by 56\%,56\% and 57\%, respectively, as compared to the vehicle control $(p<0.05)$. However, there was no significant difference in metabolic activity between cultures treated with BRP at $200 \mu \mathrm{g} / \mathrm{mL}$ and the vehicle $(p>0.05)$.

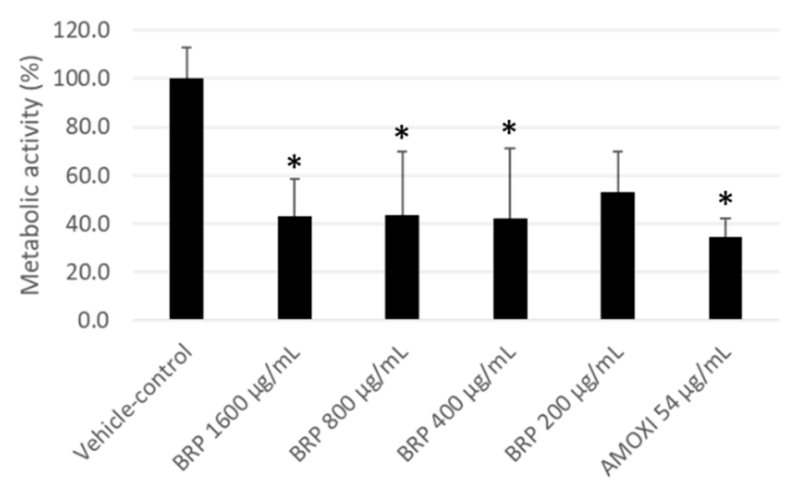

Figure 1. Metabolic activity of multispecies biofilm cultures treated with the dilution vehicle (negative control), Brazilian Red Propolis (BRP) ethanolic extract (1600, 800, 400 and $200 \mu \mathrm{g} / \mathrm{mL}$ ) and amoxicillin (AMOXI) $(54 \mu \mathrm{g} / \mathrm{mL})$. Vehicle-treated biofilms were considered as with $100 \%$ metabolic activity. ${ }^{*}$ ) indicates significant differences when compared to the control group (Kruskal-Wallis followed by Dunn's post-hoc test, $p \leq 0.05)$.

Since the extract concentration of $200 \mu \mathrm{g} / \mathrm{mL}$ did not reduce biofilm metabolic activity, we did not include this treatment group in the checkerboard DNA-DNA hybridization analysis. Figure 2 shows the mean total counts of biofilm cells treated with BRP $(1600,800$ and $400 \mu \mathrm{g} / \mathrm{mL})$ and AMOXI $(54 \mu \mathrm{g} / \mathrm{mL})$. All treatment groups were different from the vehicle control $(p<0.05)$, with no significant difference between them $(p>0.05)$. Interestingly, no significant difference in total cell counts was 
observed between biofilm cultures treated with BRP extract, regardless of the tested concentration, and those treated with the standard drug AMOXI $(p>0.05)$.

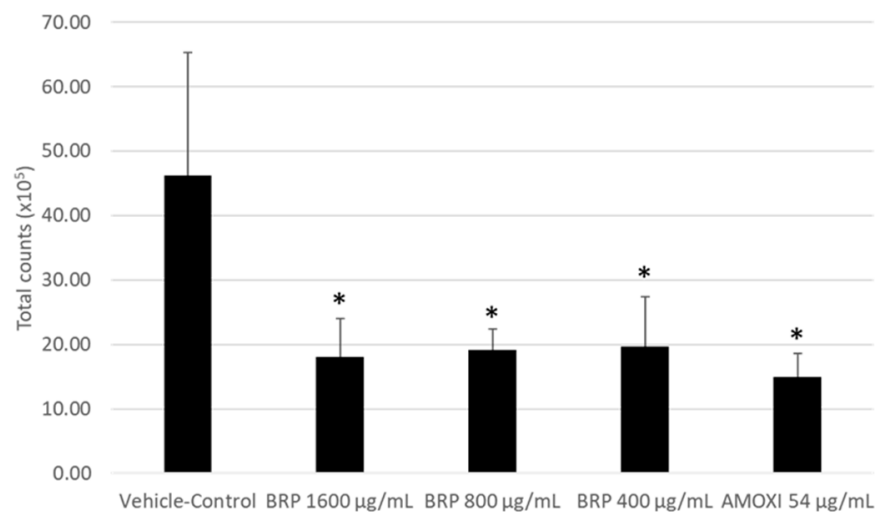

Figure 2. Total bacterial counts $\left(\times 10^{5}\right)$ in biofilms treated with the BRP ethanolic extract at 1600, 800 and $400 \mu \mathrm{g} / \mathrm{mL}$ and amoxicillin (AMOXI) at $\left.54 \mu \mathrm{g} / \mathrm{mL} .{ }^{*}\right)$ indicates a significant difference when compared to the control group (Kruskal-Wallis followed by Dunn's post-hoc test, $p \leq 0.05$ ).

As there was no statistical difference between the three tested concentrations of BRP extract, the lowest effective concentration was selected for further analysis. Figure 3 shows that treatment with BRP $(400 \mu \mathrm{g} / \mathrm{mL})$ and AMOXI $(54 \mu \mathrm{g} / \mathrm{mL})$ significantly reduced the proportions of red-complex (disease-associated), green- and yellow-complex (health-associated) bacterial strains and that only AMOXI decreased the proportions of Actinomyces species, as compared to the control group $(p<0.05)$.
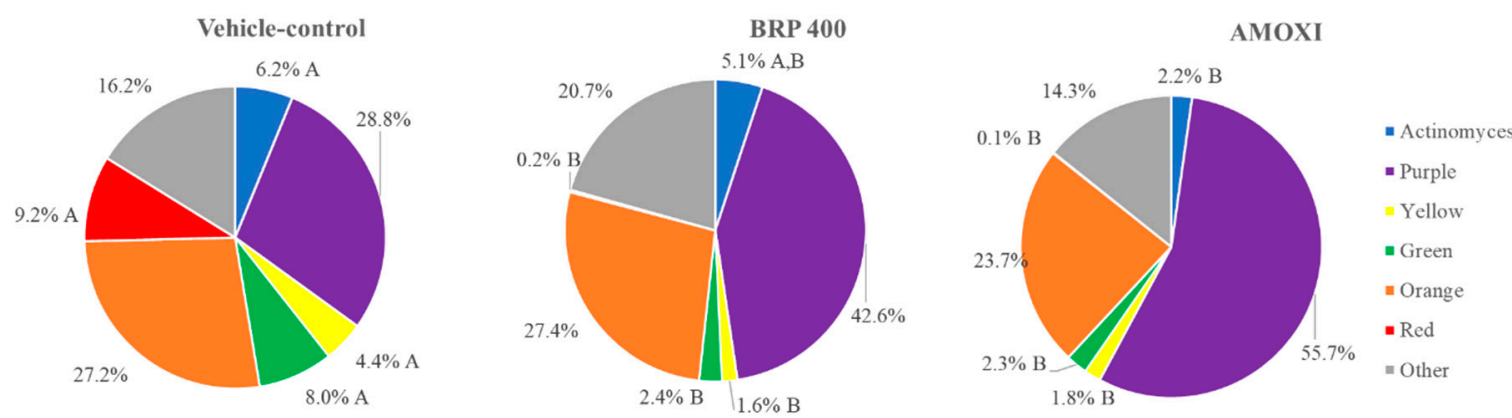

Figure 3. The effects of Brazilian Red Propolis (BRP) extract, amoxicillin (AMOXI) and vehicle control on the proportion of bacterial complexes. The colors represent different microbial complexes as described by Socransky et al., 1998. The data were analyzed by Kruskal-Wallis followed by Dunn's post-hoc test. Different letters indicate significant differences between groups within the same bacterial complex $(p \leq 0.05)$.

Figure 4 shows the mean total counts of each bacterial strain in treated biofilms. Treatment with BRP $(400 \mu \mathrm{g} / \mathrm{mL})$ and AMOXI $(54 \mu \mathrm{g} / \mathrm{mL})$ reduced the mean counts of eight different species (Actinomyces gerencseriae, Capnocytophaga ochracea, Capnocytophaga gingivalis, Prevotella intermedia, Porphyromonas gingivalis, Tannerella forsythia, Streptococcus anginosus and Streptococcus mutans) when compared to vehicle-treated biofilms $(p<0.05)$. Streptococcus sanguinis counts were significantly reduced only in BRP-treated biofilms, whereas Streptococcus oralis, Streptococcus gordonii, Actinomyces israelii and Fusobacterium nucleatum vincentii counts were reduced only in AMOXI-treated biofilms, as compared to the control group $(p<0.05)$. 


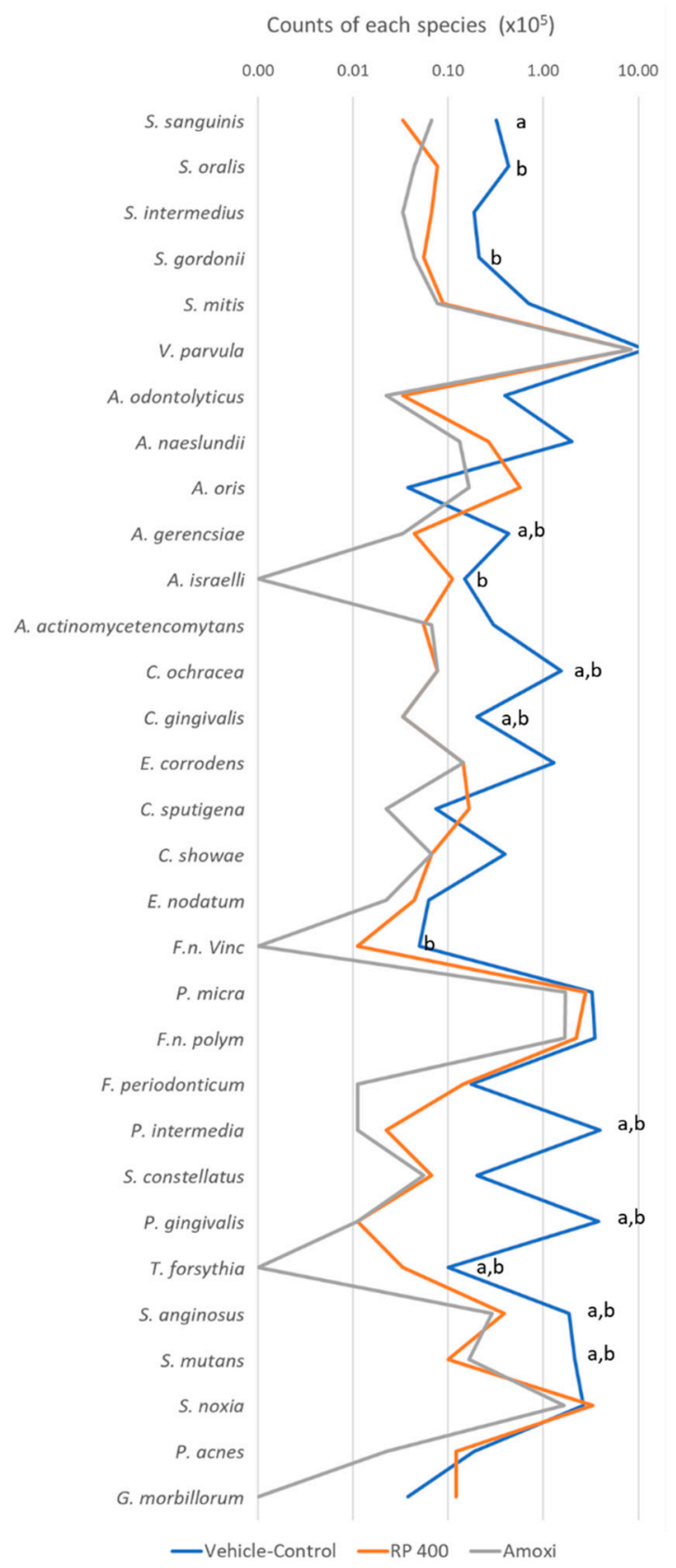

Figure 4. Mean total counts of bacterial strains in biofilms treated with the vehicle control, BRP extract $(400 \mu \mathrm{g} / \mathrm{mL})$ and amoxicillin (AMOXI) $(54 \mu \mathrm{g} / \mathrm{mL})$. The data were analyzed by Kruskal-Wallis followed by Dunn's post-hoc test $(p<0.05)$. Letter "a" indicates statistically significant differences between BRP $(400 \mu \mathrm{g} / \mathrm{mL})$ and the vehicle-control but no difference between BRP (400 $\mu \mathrm{g} / \mathrm{mL})$ and AMOXI; letter " $\mathrm{b}$ " indicates statistically significant differences between AMOXI and the vehicle-control but no difference between AMOXI and BRP $(400 \mu \mathrm{g} / \mathrm{mL})$.

\section{Discussion}

Our study showed that BRP extract was effective in reducing the metabolic activity and total cell counts of red-complex strains in mature biofilms similarly to AMOXI. Moreover, both substances significantly reduced the mean counts of eight bacterial species, including well-known periodontal pathogens, such as P. gingivalis, T. forsythia and P. intermedia, while the proportions of the host compatible Actinomyces species were only reduced by AMOXI. 
Subgingival biofilms associated with periodontitis are classically categorized into color-coded complexes, according to their role in periodontal health or disease. The red complex is composed by microorganisms associated with disease; the orange complex is associated with the health-disease transition, while the yellow, purple and green complexes as well as Actinomyces species are associated with a healthy periodontal condition [23]. It has been well established that pathogens in the red and orange complexes may trigger and/or sustain the dysbiosis state in biofilms associated with periodontitis, thereby leading to a persistent, exacerbated and damaging inflammatory response [1]. Thus, the effects of BRP in reducing the proportion of red-complex pathogens, such as P. gingivalis and T. forsythia, similarly to a potent antibiotic such as AMOXI, was considered a remarkable result.

A recent study showed that BRP extract was able to reduce the proportions of red and orange bacterial complexes at the concentration of $1600 \mu \mathrm{g} / \mathrm{mL}$, while chlorhexidine reduced only those from the red complex [13]. The differences between our findings and those of Miranda et al. [13] can be explained by the treatment regimen used in our studies. While Miranda et al. [13] performed two 1 min daily treatments during biofilm formation, we grew biofilm cultures for six days to a mature state and then treated them for $24 \mathrm{~h}$. This protocol was selected to mimic the systemic use of antibiotics, which are normally administered for one/two week(s). Although mature biofilms are more resistant to antimicrobials than immature biofilms, the effective concentration of BRP extract for a $24 \mathrm{~h}$ treatment $(400 \mu \mathrm{g} / \mathrm{mL})$ was four-fold lower than that used for daily treatments $(1600 \mu \mathrm{g} / \mathrm{mL})$ [13]. Once the contact period of the BRP extract with biofilm cells was longer in our study, we reasoned that testing a lower effective concentration of the extract would be more appropriate, particularly because our findings showed that increasing BRP extract concentration above $400 \mu \mathrm{g} / \mathrm{mL}$ does not augment the inhibitory effects of the extract against mature biofilms.

An intriguing result observed in our study was that AMOXI-treated biofilms showed lower proportions of beneficial Actinomyces species. Interestingly, a previous clinical study showed a considerable decrease in the proportions of Actinomyces species up to one year after AMOXI administration in a group of adults with periodontitis. This may be considered an undesired effect of AMOXI since species of the genus Actinomyces have been closely related to rebiosis $[4,6,24]$.

The combination of AMOXI and MTZ with SRP has been well studied and has shown clinically relevant benefits for the treatment of severe periodontitis and killing of subgingival pathogens [6]. However, another study using the same in vitro subgingival biofilm model showed that administration of AMOXI alone or AMOXI plus MTZ for a period of $24 \mathrm{~h}$ has similar effects on biofilm metabolic activity [25]. Therefore, in the present study, we used only AMOXI as a positive control. The concentration of AMOXI $(54 \mu \mathrm{g} / \mathrm{mL})$ used in our study was the most effective one from a range of concentrations previously tested in a $24 \mathrm{~h}$ treatment [25]. Consistent with the findings reported by Soares et al., our study showed a very similar effectiveness of AMOXI in reducing biofilm metabolic activity by $65 \%$.

While systemic antibiotics are clinically effective, there have been reports of side effects [7] and, more importantly, a significant increase in antibiotic resistance rates worldwide [26]. Altogether, this scenario has encouraged researchers to constantly seek novel candidates for co-adjuvant periodontal therapy, such as propolis, probiotics and resolvins [27-30]. The interplay between microbial dysbiosis and inflammation on the onset and progression of periodontal diseases has been a topic of debate, and apparently, BRP extract seems to have effectivity on both aspects. It has been recently shown in vitro and in vivo that BRP can modulate the inflammatory process by inhibiting the Toll-like response and the NF- $\mathrm{KB}$ pathway, an important inflammatory mediator [16-18,31]. In addition, our findings and others reported elsewhere [13] indicate that BRP extract has an excellent killing effect against periodontal pathogens during biofilm formation. These data suggest that BRP holds concomitant anti-inflammatory and antibacterial properties. Its complex chemical composition, including the presence of formonetin, medicarpin, neovestitol and vestitol, may explain the major antimicrobial and anti-inflammatory properties displayed by the extract [14,32]. 
Isolating and purifying fractions from natural products is a relevant and novel strategy in drug discovery and development. Working with crude extracts may prove a challenging task due to their complex chemical composition and the common presence of compounds with unknown polarity and solubility [33]. A fraction containing both neovestitol and vestitol, which are compounds isolated from BRP, showed significant activity against Streptococcus mutans biofilms [34]. Thus, the neovestitol/vestitol fraction of BRP should be further tested in subgingival biofilm models. Additionally, these compounds were shown to have anti-inflammatory properties when tested isolated. Both neovestitol and vestitol were reported to modulate the NF- $\mathrm{kB}$ pathway in lipopolysaccharide (LPS)-activated macrophages [35,36] and decreased neutrophil migration, rolling and adhesion, by reducing the expression of ICAM-1 in an in vivo LPS-induced acute peritonitis model [37,38]. Lastly, a recent study also showed that these compounds downregulated the expression of proteins commonly used as targets for cancer treatment [39].

Despite the body of evidence showing the beneficial properties of BRP, its clinical use still warrants further research. Since most of the published articles on this topic report laboratorial or animal studies, the safety and possible toxicity of BRP in humans remain to be determined.

\section{Materials and Methods}

\subsection{Preparation of BRP Extract}

BRP samples were collected in a private farm in the city of Maceio, Alagoas State, northeastern Brazil. The samples were scraped off the boxes in which they were transported, which also contained Apis mellifera bees. Any residues of bee wax or other materials were removed. The chemical analysis of BRP samples was previously performed by our research group [16]. High-performance liquid chromatography revealed the main compounds found in BRP samples were formononetin, vestitol, neovestitol, quercetin, liquiritigenin and isoliquiritigenin [16], which is in accordance with the literature [14,15,31]. Briefly, the BRP ethanolic extract was obtained by adding $25 \mathrm{~g}$ of red propolis into $200 \mathrm{~mL}$ of $80 \%$ ethanol/ $20 \%$ water $(v / v)$ under continuous mixing for $45 \mathrm{~min}$. Next, the suspension was filtered with qualitative filter paper $(80 \mathrm{~g})$ to remove any possible impurity, the solvent was evaporated using a rotary evaporator equipment, and the BRP ethanolic extract was obtained, with a yield of $73 \%$ (from $100 \mathrm{~g}$ of red propolis, $73 \mathrm{~g}$ of BRP ethanolic extract was obtained). The extract was kept at $4{ }^{\circ} \mathrm{C}$ and protected from light to prevent stability loss. The BRP ethanolic extract was re-diluted in $80 \%$ ethanol to obtain concentrations of 3200, 1600, 800 and $400 \mu \mathrm{g} / \mathrm{mL}$. Prior to biofilm treatments, the BRP extracts were diluted 1:1 with the culture media, with final treatment concentrations as $1600,800,400$ and $200 \mu \mathrm{g} / \mathrm{mL}$. The final ethanol concentration in the extract used in the treatment was $3.2 \%$.

\subsection{In Vitro Multispecies Biofilm Model}

In vitro multispecies biofilm cultures were prepared as described by Miranda et al. [13], with some modifications. The bacterial species included in the biofilm model are listed in Table 1.

Tryptone soy agar with $5 \%$ sheep blood (Probac, São Paulo, Brazil) was used to grow most species under anaerobic conditions, $85 \%$ nitrogen, $10 \%$ carbon dioxide and $5 \%$ hydrogen, while Eubacterium nodatum were cultured on fastidious anaerobic agar with $5 \%$ sheep blood. Porphyromonas gingivalis was grown on tryptone soy agar containing yeast extract enriched with $1 \%$ hemin, $5 \%$ menadione and $5 \%$ sheep blood. Tannerella forsythia was grown on tryptone soy agar containing yeast extract enriched with $1 \%$ hemin, $5 \%$ menadione, $5 \%$ sheep blood and $1 \% \mathrm{~N}$-acetylmuramic acid. All species were allowed to grow on agar plates for $24 \mathrm{~h}$ and then transferred to glass tubes containing BHI culture medium (Becton Dickinson, Sparks, MD, USA) supplemented with $1 \%$ hemin. After $24 \mathrm{~h}$ growing on conical tubes, the optical density (OD) was adjusted for the inoculum to have about $10^{8} \mathrm{cells} / \mathrm{mL}$ of each species. A dilution of individual cell suspensions was performed, and $100 \mu \mathrm{L}$ aliquots containing $10^{6}$ cells from each species were added to $11,700 \mu \mathrm{L}$ of BHI broth complemented with $1 \%$ hemin and $5 \%$ sheep blood to obtain an inoculum of $15 \mathrm{~mL}$. 
Table 1. List of bacterial species cultured in multispecies biofilms. The strains were categorized into the microbial complexes described by Socransky et al. [25].

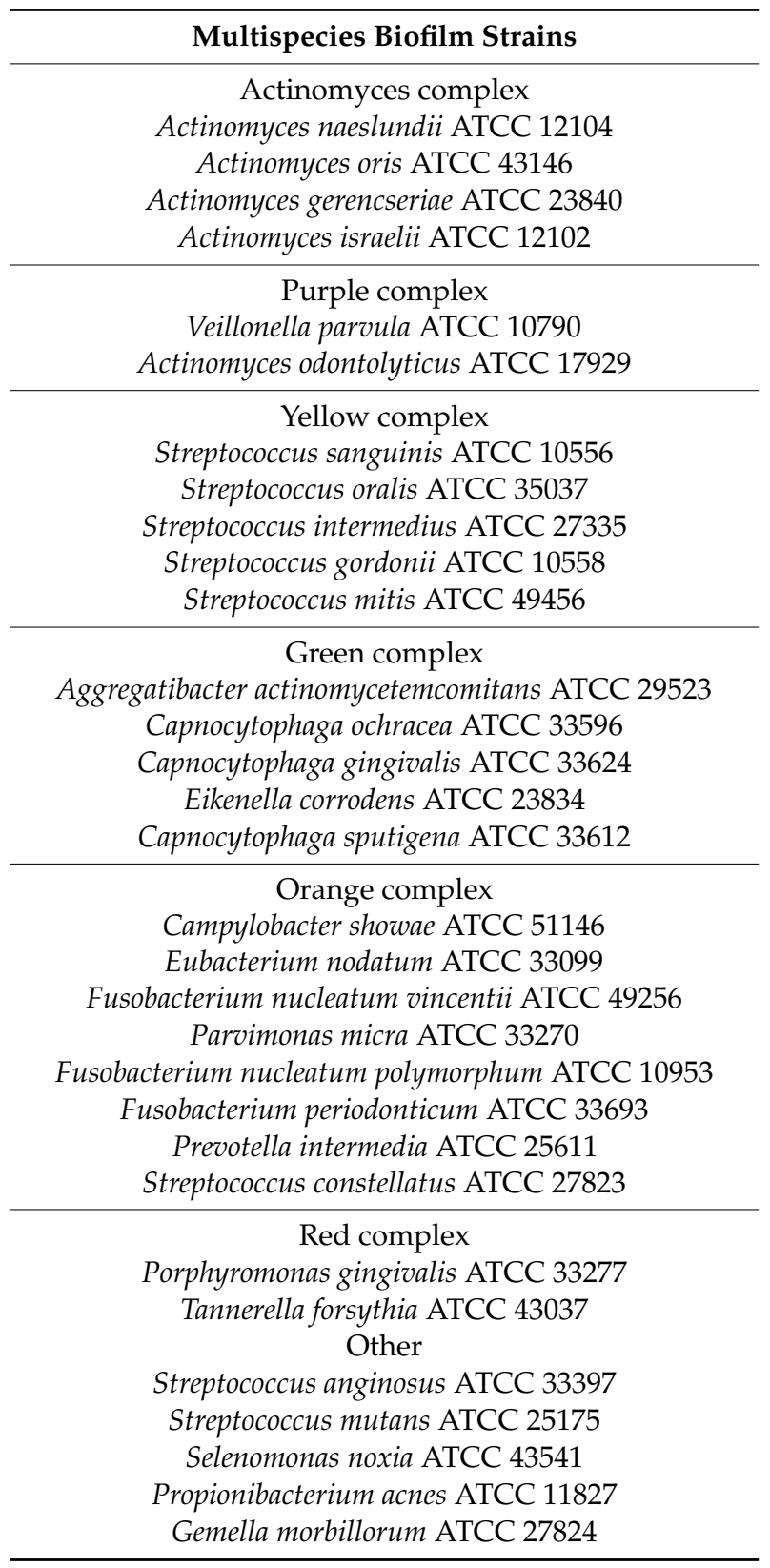

The multispecies biofilm model was developed using a Calgary biofilm device (CBD) in a 96-well plate (Nunc; Thermo Scientific, Roskilde, Denmark). A $150 \mu \mathrm{L}$ aliquot of each inoculum was added to the wells and corresponded to $\sim 1 \times 10^{4}$ cells of each bacterial strain, except for P. gingivalis and Prevotella intermedia, whose inocula were adjusted to $2 \times 10^{4}$ cells. A lid containing polystyrene pins was used to seal the 96-well plate (Nunc TSP system; Thermo Scientific, Roskilde, Denmark). Coated plates were incubated at $37^{\circ} \mathrm{C}$ under anaerobic conditions. On day three, the spent medium (BHI broth with $1 \%$ hemin and $5 \%$ sheep blood) was replaced, and biofilm cultures were kept at $37^{\circ} \mathrm{C}$ under anaerobic conditions for an additional four days to obtain seven-day-old biofilms [13].

\subsection{Treatments with BRP Extract}

Biofilm cultures were treated with the BRP extract for $24 \mathrm{~h}$ after six days of biofilm development. Biofilm-coated CBD pins were transferred to 96-well plates containing culture media plus the BRP 
ethanolic extract $(1600,800,400$ or $200 \mu \mathrm{g} / \mathrm{mL})$, dilution vehicle (negative control) and AMOXI at $54 \mu \mathrm{g} / \mathrm{mL}$ (positive control). All groups were diluted with culture media at a 1:1 ratio. The vehicle control was the same solution used to dissolve the BRP extract and consisted of $6.4 \%$ ethanol in $10 \%$ phosphate buffer $(v / v$, final concentration: 3.2\%). After treatment, the pins were washed with PBS and submitted to biological tests, as following described.

\subsection{Quantification of Biofilm Metabolic Activity}

The effects of BRP extract and controls on the metabolic activity of multispecies biofilm cells were measured in a spectrophotometric assay with 2,3,5-triphenyltetrazolium chloride (TTC) (catalog No. 17779; Fluka analytical). TTC is used to differentiate between metabolically active and inactive cells. TCC white substrate is enzymatically reduced to red formazan 1,3,5-triphenyl by live cells due to the activity of several dehydrogenases. The change in substrate color is an indirect measure of bacterial metabolic activity.

To measure the metabolic activity of biofilm cells, the pins were transferred to 96-well plates with $200 \mu \mathrm{L} /$ well of fresh BHI medium supplemented with $1 \%$ hemin and $0.1 \%$ TTC solution. The plates were incubated under anaerobic conditions for $8 \mathrm{~h}$ at $37^{\circ} \mathrm{C}$. TTC reduction to red formazan was read at $485 \mathrm{~nm}$ in a spectrophotometer [13].

\subsection{Checkerboard DNA-DNA Hybridization}

The pins coated with seven-day-old biofilms from each group were transferred to Eppendorf tubes containing $100 \mu \mathrm{L}$ of TE buffer (10 mM Tris-HCl, 1 mM EDTA (pH 7.6)); then, $100 \mu \mathrm{L}$ of $0.5 \mathrm{M} \mathrm{NaOH}$ was added to each tube. The tubes containing the pins and the final solution were boiled for $10 \mathrm{~min}$, and the solution was neutralized by adding $0.8 \mathrm{~mL}$ of $5 \mathrm{M}$ ammonium acetate. The samples were individually analyzed for the presence and count of the 31 bacterial species using the DNA-DNA hybridization technique, as previously described (Socransky et al., 1994; Mestnik et al., 2010). Briefly, following sample lysis, the DNA was placed onto a nylon membrane using a Minislot device (Immunetics, Cambridge, USA) and fixed onto the membrane at $120^{\circ} \mathrm{C}$ for $20 \mathrm{~min}$. Next, the membrane was placed in a Miniblotter 45 (Immunetics). Digoxigenin-labelled whole genomic DNA probes of the 31 bacterial species were hybridized in each lane of the Miniblotter. Following hybridization, the membranes were washed, and DNA probes were detected using a specific antibody to digoxigenin conjugated with phosphatase alkaline. The signals were detected using AttoPhos substrate (Amersham Life Sciences, Arlington Heights, USA), and the data were obtained in Typhoon Trio Plus program (Molecular Dynamics, Sunnyvale, USA). Two lanes in each membrane contained the standards with $1 \times 10^{5}$ and $1 \times 10^{6}$ cells of each strain. The signals were converted into absolute counts via comparison with the standards on the same membrane. Failure to detect a signal was recorded as zero. The measurements of the experimental groups were compared against those of the negative and positive controls. Counts below the method detection limit $\left(1 \times 10^{4}\right)$ were considered zero [40].

\subsection{Statistical Analysis}

The metabolic activity data were analyzed by Kruskal-Wallis followed by Dunn's post-hoc test, whereas the microbial composition (checkerboard DNA-DNA hybridization) data were analyzed using Kruskal-Wallis followed by Dunn's post-hoc test. A 5\% significance level was considered in all statistical tests.

\section{Conclusions}

Collectively, our findings showed that BRP (at a minimal concentration of $400 \mu \mathrm{g} / \mathrm{mL}$ ) extract was as effective as $54 \mu \mathrm{g} / \mathrm{mL}$ of AMOXI in killing seven-day-old multispecies biofilm pathogens and did not affect beneficial Actinomyces spp. growth. This suggests that BRP may be an alternative to AMOXI as an adjunct in periodontal therapy, but in vivo studies are needed to validate these results. 
Author Contributions: Conceptualization, H.D.P.d.S., L.C.d.F., M.F. and B.B.-S.; methodology, K.A.d.F., S.L.F.M., F.J.d.S.G., A.P.d.S. and B.B.-S.; data analysis: L.C.d.F., H.D.P.d.S., M.F. and B.B.-S.; resources, B.B.-S., L.C.d.F. and M.F.; writing — original draft preparation, K.A.d.F. and B.B.-S.; writing—review and editing, H.D.P.d.S., L.C.d.F., M.F. and B.B.-S. All authors have read and agreed to the published version of the manuscript.

Funding: The APC was funded by the Coordination for the Improvement of Higher Education Personnel (CAPES, Brazil) through the PROEX program (grant number 0475/2019, process number 23038.005614/2019-74).

Conflicts of Interest: The authors declare no conflicts of interest.

\section{References}

1. Hajishengallis, G. Periodontitis: From microbial immune subversion to systemic inflammation. Nature reviews. Immunology 2015, 15, 30-44. [CrossRef] [PubMed]

2. Durham, J.; Fraser, H.M.; McCracken, G.I.; Stone, K.M.; John, M.T.; Preshaw, P.M. Impact of periodontitis on oral health-related quality of life. J. Dent. 2013, 41, 370-376. [CrossRef] [PubMed]

3. Teles, R.P.; Haffajee, A.D.; Socransky, S.S. Microbiological goals of periodontal therapy. Periodontol. 2000 2006, 42, 180-218. [CrossRef] [PubMed]

4. Feres, M.; Haffajee, A.D.; Allard, K.; Som, S.; Socransky, S.S. Change in subgingival microbial profiles in adult periodontitis subjects receiving either systemically-administered amoxicillin or metronidazole. J. Clin. Periodontol. 2001, 28, 597-609. [CrossRef]

5. Abu-Fanas, S.H.; Drucker, D.B.; Hull, P.S.; Reeder, J.C.; Ganguli, L.A. Identification, and susceptibility to seven antimicrobial agents, of 61 gram-negative anaerobic rods from periodontal pockets. J. Dent. 1991, 19, 46-50. [CrossRef]

6. Feres, M.; Figueiredo, L.C.; Soares, G.M.; Faveri, M. Systemic antibiotics in the treatment of periodontitis. Periodontology 2000 2015, 67, 131-186. [CrossRef]

7. Teughels, W.; Feres, M.; Oud, V.; Martin, C.; Matesanz, P.; Herrera, D. Adjunctive effect of systemic antimicrobials in periodontitis therapy. A systematic review and meta-analysis. J. Clin. Periodontol. 2020. [CrossRef]

8. Cionca, N.; Giannopoulou, C.; Ugolotti, G.; Mombelli, A. Microbiologic testing and outcomes of full-mouth scaling and root planing with or without amoxicillin/metronidazole in chronic periodontitis. J. Periodontol. 2010, 81, 15-23. [CrossRef]

9. Kouidhi, B.; Al Qurashi, Y.M.; Chaieb, K. Drug resistance of bacterial dental biofilm and the potential use of natural compounds as alternative for prevention and treatment. Microb. Pathog. 2015, 80, 39-49. [CrossRef]

10. Newman, D.J.; Cragg, G.M. Natural Products as Sources of New Drugs from 1981 to 2014. J. Nat. Prod. 2016, 79, 629-661. [CrossRef]

11. Jeon, J.G.; Rosalen, P.L.; Falsetta, M.L.; Koo, H. Natural Products in Caries Research: Current (Limited) Knowledge, Challenges and Future Perspective. Caries Res. 2011, 45, 243-263. [CrossRef]

12. Silva, B.B.; Rosalen, P.L.; Cury, J.A.; Ikegaki, M.; Souza, V.C.; Esteves, A.; Alencar, S.M. Chemical composition and botanical origin of red propolis, a new type of brazilian propolis. Evid. Based Complementary Altern. Med. 2008, 5, 313-316. [CrossRef]

13. Miranda, S.L.F.; Damasceno, J.T.; Faveri, M.; Figueiredo, L.; da Silva, H.D.; Alencar, S.M.A.; Rosalen, P.L.; Feres, M.; Bueno-Silva, B. Brazilian red propolis reduces orange-complex periodontopathogens growing in multispecies biofilms. Biofouling 2019, 1-12. [CrossRef]

14. Bueno-Silva, B.; Marsola, A.; Ikegaki, M.; Alencar, S.M.; Rosalen, P.L. The effect of seasons on Brazilian red propolis and its botanical source: Chemical composition and antibacterial activity. Nat. Prod. Res. 2017, 31, 1318-1324. [CrossRef]

15. Dantas Silva, R.P.; Machado, B.A.; Barreto, G.A.; Costa, S.S.; Andrade, L.N.; Amaral, R.G.; Carvalho, A.A.; Padilha, F.F.; Barbosa, J.D.; Umsza-Guez, M.A. Antioxidant, antimicrobial, antiparasitic, and cytotoxic properties of various Brazilian propolis extracts. PLoS ONE 2017, 12, e0172585. [CrossRef]

16. Bueno-Silva, B.; Kawamoto, D.; Ando-Suguimoto, E.S.; Casarin, R.C.V.; Alencar, S.M.; Rosalen, P.L.; Mayer, M.P.A. Brazilian red propolis effects on peritoneal macrophage activity: Nitric oxide, cell viability, pro-inflammatory cytokines and gene expression. J. Ethnopharmacol. 2017, 207, 100-107. [CrossRef] 
17. Bueno-Silva, B.; Franchin, M.; Alves, C.F.; Denny, C.; Colon, D.F.; Cunha, T.M.; Alencar, S.M.; Napimoga, M.H.; Rosalen, P.L. Main pathways of action of Brazilian red propolis on the modulation of neutrophils migration in the inflammatory process. Phytomedicine Int. J. Phytother. Phytopharm. 2016, 23, 1583-1590. [CrossRef]

18. Bueno-Silva, B.; Kawamoto, D.; Ando-Suguimoto, E.S.; Alencar, S.M.; Rosalen, P.L.; Mayer, M.P. Brazilian Red Propolis Attenuates Inflammatory Signaling Cascade in LPS-Activated Macrophages. PLoS ONE 2015, 10, e0144954. [CrossRef]

19. Frozza, C.; Santos, D.A.; Rufatto, L.C.; Minetto, L.; Scariot, F.J.; Echeverrigaray, S.; Pich, C.T.; Moura, S.; Padilha, F.F.; Borsuk, S.; et al. Antitumor activity of Brazilian red propolis fractions against Hep-2 cancer cell line. Biomed. Pharmacother. Biomed. Pharmacother. 2017, 91, 951-963. [CrossRef] [PubMed]

20. Correa, F.R.; Schanuel, F.S.; Moura-Nunes, N.; Monte-Alto-Costa, A.; Daleprane, J.B. Brazilian red propolis improves cutaneous wound healing suppressing inflammation-associated transcription factor NFkappaB. Biomed. Pharmacother. Biomed. Pharmacother. 2017, 86, 162-171. [CrossRef]

21. Jiao, Y.; Tay, F.R.; Niu, L.N.; Chen, J.H. Advancing antimicrobial strategies for managing oral biofilm infections. Int. J. Oral Sci. 2019, 11, 28. [CrossRef] [PubMed]

22. Kuang, X.; Chen, $\mathrm{V}$.; Xu, X. Novel Approaches to the Control of Oral Microbial Biofilms. Biomed. Res. Int. 2018, 2018, 6498932. [CrossRef] [PubMed]

23. Socransky, S.S.; Haffajee, A.D.; Cugini, M.A.; Smith, C.; Kent, R.L., Jr. Microbial complexes in subgingival plaque. J. Clin. Periodontol. 1998, 25, 134-144. [CrossRef]

24. Teles, R.P.; Bogren, A.; Patel, M.; Wennstrom, J.L.; Socransky, S.S.; Haffajee, A.D. A three-year prospective study of adult subjects with gingivitis II: Microbiological parameters. J. Clin. Periodontol. 2007, 34, 7-17. [CrossRef]

25. Soares, G.M.; Teles, F.; Starr, J.R.; Feres, M.; Patel, M.; Martin, L.; Teles, R. Effects of azithromycin, metronidazole, amoxicillin, and metronidazole plus amoxicillin on an in vitro polymicrobial subgingival biofilm model. Antimicrob. Agents Chemother. 2015, 59, 2791-2798. [CrossRef]

26. Jepsen, K.; Jepsen, S. Antibiotics/antimicrobials: Systemic and local administration in the therapy of mild to moderately advanced periodontitis. Periodontol. 2000 2016, 71, 82-112. [CrossRef]

27. Kuru, B.E.; Laleman, I.; Yalnizoglu, T.; Kuru, L.; Teughels, W. The Influence of a Bifidobacterium animalis Probiotic on Gingival Health: A Randomized Controlled Clinical Trial. J. Periodontol. 2017, 88, 1115-1123. [CrossRef]

28. Matsubara, V.H.; Bandara, H.M.; Ishikawa, K.H.; Mayer, M.P.; Samaranayake, L.P. The role of probiotic bacteria in managing periodontal disease: A systematic review. Expert Rev. Anti Infect. Ther. 2016, 14, 643-655. [CrossRef]

29. Mizraji, G.; Heyman, O.; Van Dyke, T.E.; Wilensky, A. Resolvin D2 Restrains Th1 Immunity and Prevents Alveolar Bone Loss in Murine Periodontitis. Front. Immunol. 2018, 9, 785. [CrossRef]

30. Van Dyke, T.E. Pro-resolving mediators in the regulation of periodontal disease. Mol. Asp. Med. 2017, 58, 21-36. [CrossRef]

31. Bueno-Silva, B.; Alencar, S.M.; Koo, H.; Ikegaki, M.; Silva, G.V.; Napimoga, M.H.; Rosalen, P.L. Anti-inflammatory and antimicrobial evaluation of neovestitol and vestitol isolated from Brazilian red propolis. J. Agric. Food Chem. 2013, 61, 4546-4550. [CrossRef] [PubMed]

32. Inui, S.; Hatano, A.; Yoshino, M.; Hosoya, T.; Shimamura, Y.; Masuda, S.; Ahn, M.R.; Tazawa, S.; Araki, Y.; Kumazawa, S. Identification of the phenolic compounds contributing to antibacterial activity in ethanol extracts of Brazilian red propolis. Nat. Prod. Res. 2014, 28, 1293-1296. [CrossRef] [PubMed]

33. Thornburg, C.C.; Britt, J.R.; Evans, J.R.; Akee, R.K.; Whitt, J.A.; Trinh, S.K.; Harris, M.J.; Thompson, J.R.; Ewing, T.L.; Shipley, S.M.; et al. NCI Program for Natural Product Discovery: A Publicly-Accessible Library of Natural Product Fractions for High-Throughput Screening. ACS Chem. Biol. 2018, 13, 2484-2497. [CrossRef] [PubMed]

34. Bueno-Silva, B.; Koo, H.; Falsetta, M.L.; Alencar, S.M.; Ikegaki, M.; Rosalen, P.L. Effect of neovestitol-vestitol containing Brazilian red propolis on accumulation of biofilm in vitro and development of dental caries in vivo. Biofouling 2013, 29, 1233-1242. [CrossRef] [PubMed]

35. Bueno-Silva, B.; Rosalen, P.L.; Alencar, S.M.; Mayer, M.P.A. Anti-inflammatory mechanisms of neovestitol from Brazilian red propolis in LPS-activated macrophages. J. Funct. Foods 2017, 36, 440-447. [CrossRef] 
36. Bueno-Silva, B.; Rosalen, P.L.; Alencar, S.M.; Mayer, M.P.A. Vestitol drives LPS-activated macrophages into M2 phenotype through modulation of NF-kappaB pathway. Int. Immunopharmacol. 2020, 82, 106329. [CrossRef]

37. Franchin, M.; Colon, D.F.; da Cunha, M.G.; Castanheira, F.V.; Saraiva, A.L.; Bueno-Silva, B.; Alencar, S.M.; Cunha, T.M.; Rosalen, P.L. Neovestitol, an isoflavonoid isolated from Brazilian red propolis, reduces acute and chronic inflammation: Involvement of nitric oxide and IL-6. Sci. Rep. 2016, 6, 36401. [CrossRef]

38. Franchin, M.; Colon, D.F.; Castanheira, F.V.; da Cunha, M.G.; Bueno-Silva, B.; Alencar, S.M.; Cunha, T.M.; Rosalen, P.L. Vestitol Isolated from Brazilian Red Propolis Inhibits Neutrophils Migration in the Inflammatory Process: Elucidation of the Mechanism of Action. J. Nat. Prod. 2016, 79, 954-960. [CrossRef]

39. Nani, B.D.; Franchin, M.; Lazarini, J.G.; Freires, I.A.; da Cunha, M.G.; Bueno-Silva, B.; de Alencar, S.M.; Murata, R.M.; Rosalen, P.L. Isoflavonoids from Brazilian red propolis down-regulate the expression of cancer-related target proteins: A pharmacogenomic analysis. Phytother. Res. Ptr 2018, 32, 750-754. [CrossRef]

40. Pingueiro, J.; Piattelli, A.; Paiva, J.; Figueiredo, L.C.; Feres, M.; Shibli, J.; Bueno-Silva, B. Additive manufacturing of titanium alloy could modify the pathogenic microbial profile: An in vitro study. Braz. Oral Res. 2019, 33, e065. [CrossRef]

(C) 2020 by the authors. Licensee MDPI, Basel, Switzerland. This article is an open access article distributed under the terms and conditions of the Creative Commons Attribution (CC BY) license (http://creativecommons.org/licenses/by/4.0/). 